\title{
Wind storm loss estimations in the Canton of Vaud (Western Switzerland)
}

\author{
C. Etienne and M. Beniston \\ Climatic Change and Climate Impacts Group, Institute for Environmental Sciences, University of Geneva, Battelle/D, \\ Chemin de Drize 7, 1227 Carouge, Geneva, Switzerland \\ Correspondence to: C. Etienne (christophe.etienne@unige.ch)
}

Received: 8 November 2011 - Revised: 15 November 2012 - Accepted: 29 November 2012 - Published: 21 December 2012

\begin{abstract}
A storm loss model that was first developed for Germany is applied to the much smaller geographic area of the canton of Vaud, in Western Switzerland. 24 major wind storms that struck the region during the period 19902010 are analysed, and outputs are compared to loss observations provided by an insurance company. Model inputs include population data and daily maximum wind speeds from weather stations. These measured wind speeds are regionalised in the canton of Vaud following different methods, using either basic interpolation techniques from Geographic Information Systems (GIS), or by using an existing extreme wind speed map of Switzerland whose values are used as thresholds. A third method considers the wind power, integrating wind speeds temporally over storm duration to calculate losses. Outputs show that the model leads to similar results for all methods, with Pearson's correlation and Spearman's rank coefficients of roughly 0.7 . Bootstrap techniques are applied to test the model's robustness. Impacts of population growth and possible changes in storminess under conditions of climate change shifts are also examined for this region, emphasizing high shifts in economic losses related to small increases of input wind speeds.
\end{abstract}

\section{Introduction}

Wind storms are one of the most costly natural hazards in Europe (SwissRe, 2000). They can cause severe damage and therefore lead to major economic losses. In Switzerland, winter storms Vivian in February 1990 (Schüepp et al., 1994) and Lothar in December 1999 (Wernli et al., 2002) were the most devastating events of the last two decades. In 1990, the Vivian storm struck particularly the Swiss Alps with record gusts of up to $74.5 \mathrm{~m} \mathrm{~s}^{-1}$, causing major destruction to the transportation sector and devastating important tracts of forests, with over 5 million $\mathrm{m}^{3}$ of wood blown to the ground. Less than $10 \mathrm{yr}$ later, the Lothar storm hit Switzerland more widely, causing severe damage to infrastructure and forests, with total economic losses estimated in excess of 10 billion Euros (Bresch et al., 2000). More recently, storm Xynthia also caused important losses in February 2010, notably due to the exceptional storm surges along the French Atlantic coast. A rise in storm-related monetary losses for Europe in the course of the 20th century has been observed by Barredo (2010), explained principally by changes in economic and demographic conditions, with much of the recent infrastructure in various parts of the world increasingly constructed in zones at risk from severe weather. Furthermore, studies show that losses related to European wind storm events are likely to increase in the 21 st century as a result of greenhouse-gas warming (e.g. Della-Marta et al., 2010; Schwierz et al., 2010).

Economic loss models have been used to calculate damage related to wind storms (Klawa and Ulbrich, 2003; Heneka and Ruck, 2004). They combine data describing a wind storm - mainly wind gusts, but also mean wind speeds (Unanwa et al., 2000) - and the spatial distribution of property values to assess economic losses related to a wind storm event. Most models consist of empirical functions that have been adjusted to historical loss data provided by insurance companies, assessing damage at different spatial scale levels, from postalcode areas (Dorland et al., 1999; Heneka et al., 2006; Pinto et al., 2010) to districts (Klawa and Ulbrich, 2003) or even countries (e.g. Leckebusch et al., 2007; Pinto et al., 2007). The wind-loss relationship was investigated in these studies, providing exponential relationships between wind speeds 




a)

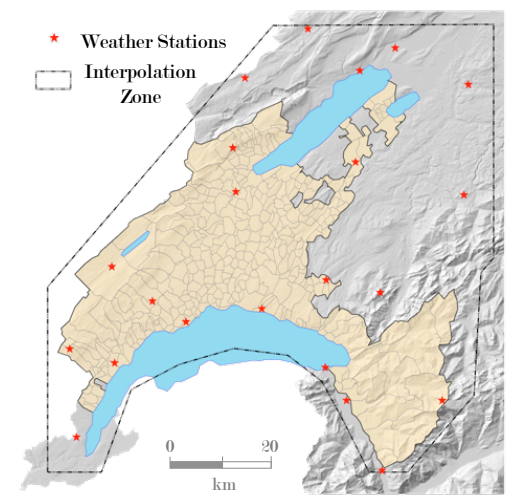

b)

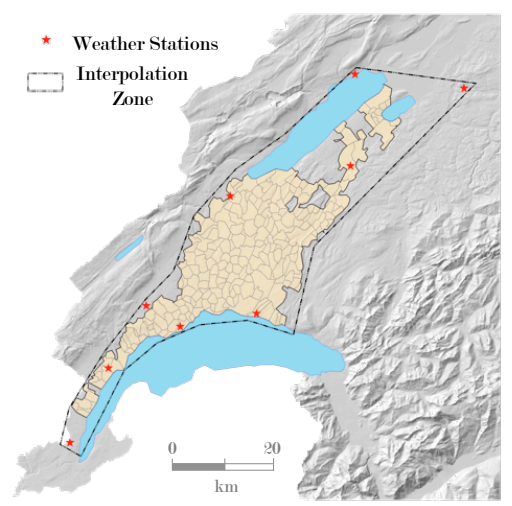

c)

Fig. 1. Maps of the canton of Vaud: (a) map showing the geographic location of Vaud in Switzerland, (b) the canton of Vaud and its 368 municipalities, with the Jura mountains to the west, the Alps to the East and the Lake of Geneva to the south. The 22 weather stations used for this study are shown, as well as the interpolation zone. Finally, (c) shows a confined and more simple interpolation zone excluding the complex alpine region and the Jura.

and related losses. Impacts of changing climate conditions as well as socio-economic factors can, moreover, be evaluated using loss models, providing estimates of costs of future storms in the 21st century (e.g. Leckebusch et al., 2007; Schwierz et al., 2010). In parallel to loss models, by integrating long-term wind statistics and subsequently estimating return periods of storm events, risks related to severe storms can be calculated (e.g. Della-Marta et al., 2009).

In this paper, a simple storm loss model is applied to the canton of Vaud, in Western Switzerland, investigating 24 winter storms of major relevance for the insurance sector that occurred in Vaud between 1990 and 2010. The loss calculation results are compared to damage data provided by a state insurance company. Wind speeds recorded at weather stations during the 24 studied storms are analysed, and the spatial distributions of both wind gusts and insured values are evaluated using tools based on geographic information systems (GIS). This study also has the objective of applying an extreme wind map of Switzerland generated in a previous study (Etienne et al., 2010) to calculate storm damage. Different geo-statistical methodologies are considered in order to apply the loss model, and outcomes are listed and discussed.

\section{Study area and data}

\subsection{Study area}

Loss estimates are carried out for the canton of Vaud, in Western Switzerland (Fig. 1a). The canton covers more than $3000 \mathrm{~km}^{2}$, is bordered to the west by the Jura Mountains, to the east by the Alps and to the south by the Lake of Geneva. In the centre, a plain stretches from the west to the northeast and is commonly referred to as the Swiss Plateau. The canton is divided into 368 municipalities. It experiences complex wind regimes, principally driven by large-scale circulation patterns, but also local winds influenced by topography, such as the "Bise" (Wanner and Furger, 1990) or the "Joran" (Bohle-Carbonell, 1991). The cold and dry "Bise", mainly induced by high-pressure situations over the North Sea, blows from the north-east and gains speed by being channelled by both the Alps and the Jura, whereas the "Joran" is generated from the north-west along the Jura Mountains following the passage of cold fronts. Moreover, the warm and dry wind called the "foehn", which is the result of strong airflows crossing the Alps, comes from the southeast (Hoinka, 1985). Like most central European regions, major storm events generally occur during the winter season (e.g. Lambert and Fyfe, 2006; Ulbrich et al., 2009). The most severe storm events of the last 2 decades were identified by analyzing daily maximum wind speeds from the weather station statistics of the canton of Vaud (Fig. 1b). Switzerland has a dense network of meteorological stations which have recorded wind speeds every 10 min since 1981, providing reliable and quality-checked data in digital form (Bantle, 1989; Begert et al., 2005). The storm detection results were matched to historical damage data, leading to a list of 24 wind storm events that were investigated in this study (Table 1).

\subsection{Storm loss model}

To assess wind storm damage to infrastructures, a loss model originally developed in Germany (Klawa and Ulbrich, 2003) is applied to the canton of Vaud (Eq. 1). In terms of data inputs, the model requires both daily maximum wind speeds at a $10 \mathrm{~m}$ height and population data. Population data serves as a proxy for the spatial distribution of insured property values that are usually difficult to obtain. The input wind speeds are normalised by the 98th percentiles of the daily maximum 
Table 1. List of the 24 studied storm events. The storm dates as well as the observed number of buildings damaged and total economic losses (in Swiss Francs, indexed to year 2000 values) are listed in columns 2, 3 and 4, respectively. Column 5 provides the loss ratios, i.e. the losses divided by the total insured sums for the canton of Vaud, expressed in CHF 0.01 per CHF 1000 insured. The last 4 columns list the economic shift (in percent) due to population growth (based on the estimated population in 2030) and enhanced wind speeds (for increases in wind speeds of $3 \%, 5 \%$ and $10 \%$, respectively): comparisons are made with the original calculated losses for each storm.

\begin{tabular}{llrrrrrrr}
\hline Storm & $\begin{array}{l}\text { Storm } \\
\text { Date }\end{array}$ & $\begin{array}{r}\text { Buildings } \\
\text { Damaged }\end{array}$ & $\begin{array}{r}\text { Storm Losses } \\
(\mathrm{CHF})\end{array}$ & $\begin{array}{r}\text { Loss Ratios } \\
\left(\times 10^{5}\right)\end{array}$ & $\begin{array}{r}\text { Population } \\
2030\end{array}$ & $\begin{array}{r}\text { Winds } \\
+3 \%\end{array}$ & $\begin{array}{r}\text { Winds } \\
+5 \%\end{array}$ & $\begin{array}{l}\text { Winds } \\
+10 \%\end{array}$ \\
\hline 1 (Vivian) & 27.02 .90 & 26 & $738^{\prime} 276$ & 0.50 & 39.7 & 23.4 & 41.2 & 94.0 \\
2 & 21.12 .93 & 15 & $23^{\prime} 450$ & 0.01 & 9.9 & 14.1 & 26.0 & 66.8 \\
3 & 28.01 .94 & 118 & $280^{\prime} 675$ & 0.18 & 16.6 & 19.5 & 32.2 & 78.3 \\
4 & 26.01 .95 & $1^{\prime} 795$ & $4^{\prime} 193^{\prime} 376$ & 2.60 & 36.6 & 24.1 & 42.6 & 97.8 \\
5 & 16.02 .95 & 52 & $166^{\prime} 940$ & 0.10 & 19.6 & 18.1 & 32.7 & 79.1 \\
6 & 13.02 .96 & 18 & $19^{\prime} 096$ & 0.01 & 9.0 & 12.9 & 23.6 & 60.1 \\
7 & 11.11 .96 & 104 & $187^{\prime} 626$ & 0.11 & 10.1 & 11.0 & 19.5 & 45.3 \\
8 & 13.02 .97 & 381 & $772^{\prime} 068$ & 0.47 & 26.1 & 23.3 & 41.3 & 95.9 \\
9 & 17.12 .97 & 677 & $1^{\prime} 556^{\prime} 511$ & 0.91 & 23.2 & 16.7 & 29.2 & 65.7 \\
10 & 05.01 .98 & 198 & $416^{\prime} 275$ & 0.24 & 19.7 & 21.0 & 35.8 & 91.2 \\
11 & 19.01 .98 & 137 & $195^{\prime} 105$ & 0.11 & 16.0 & 20.0 & 36.3 & 88.8 \\
12 & 12.12 .99 & 936 & $2^{\prime} 464^{\prime} 229$ & 1.40 & 30.9 & 24.1 & 42.4 & 97.1 \\
13 (Lothar) & 26.12 .99 & $16^{\prime} 663$ & $54^{\prime} 762^{\prime} 250$ & 72.15 & 32.5 & 20.0 & 34.8 & 77.4 \\
14 & 16.02 .00 & 9 & $19^{\prime} 855$ & 0.01 & 6.3 & 10.6 & 19.7 & 51.3 \\
15 & 06.11 .00 & 411 & $1^{\prime} 415^{\prime} 513$ & 0.79 & 17.6 & 16.0 & 28.2 & 64.4 \\
16 & 14.12 .01 & 731 & $1^{\prime} 846^{\prime} 714$ & 1.02 & 11.6 & 14.6 & 26.8 & 68.3 \\
17 & 02.01 .03 & 329 & $574^{\prime} 975$ & 0.31 & 22.3 & 22.7 & 40.2 & 93.2 \\
18 & 12.01 .04 & 51 & $127^{\prime} 038$ & 0.07 & 12.9 & 17.8 & 32.2 & 78.6 \\
19 & 23.11 .05 & 160 & $406^{\prime} 403$ & 0.21 & 16.1 & 17.9 & 32.3 & 78.6 \\
20 & 01.01 .07 & 39 & $138^{\prime} 454$ & 0.07 & 8.8 & 14.4 & 25.9 & 62.6 \\
21 & 03.12 .07 & 316 & $979^{\prime} 530$ & 0.50 & 16.7 & 19.4 & 34.1 & 77.4 \\
22 (Klaus) & 23.01 .09 & 504 & $1^{\prime} 242^{\prime} 309$ & 0.63 & 15.2 & 23.3 & 41.2 & 95.4 \\
23 & 10.02 .09 & 728 & $1^{\prime} 451^{\prime} 722$ & 0.74 & 13.7 & 23.4 & 41.7 & 98.2 \\
24 (Xynthia) & 28.02 .10 & $1^{\prime} 118$ & $2^{\prime} 637^{\prime} 036$ & 1.32 & 11.8 & 18.5 & 32.5 & 74.4 \\
\hline
\end{tabular}

wind speeds $\left(v_{98}\right)$, which supposes that damage only occurs when wind gusts exceed a certain threshold, here represented by the $v_{98}$ values.

Storm Loss $\approx$

$$
A \cdot \underbrace{\sum_{\text {area }} \text { population (area) } \cdot \underbrace{\sum_{\text {for } v_{\max }>v_{98}, \text { else }=0}^{\left(\frac{v_{\max }(\text { area })}{v_{98}(\text { area })}-1\right)}}_{\text {area }}}_{\text {loss index }}+B
$$

This approach assumes that buildings are adapted to local weather conditions, since $v_{98}$ values are indeed good indicators of local extreme wind conditions. Furthermore, wind velocities are to the third power, according to physical arguments and empirical evidence (MunichRe, 2001), meaning that calculated losses are highly sensitive to input wind speed values. Both the population and the wind speed terms need to be assessed for different areas - which are here the municipalities of the canton of Vaud - before being summed up to calculate damage over the entire domain. Coefficients $A$ and $B$ are the regression coefficients that fit the calculated loss indices to the observed damage. A complete description of the storm loss model can be found in Klawa and Ulbrich (2003), for example. This model has been widely used, notably in Germany (e.g. Donat et al., 2011), especially to assess losses under future climate conditions (e.g. Leckebusch et al., 2007; Pinto et al., 2007).

\subsection{Insurance data}

Historical wind storm damage data to infrastructure is provided by a state insurance company. The total monetary losses and the number of damaged buildings are available for each of the 24 wind storms listed in Table 1. Insurance penetration in the canton of Vaud exceeds $90 \%$ such that this data provides an almost complete overview of the value distribution in the area. All values are in Swiss Francs (CHF) and are indexed to year 2000 values according to the consumer price index. The 1999 Lothar storm clearly surpasses the other storms with losses exceeding CHF 126 million, which represents more than 5 times the sum of the other 23 storms. However, information regarding the 1999 Lothar storm might also include damage data related to the Martin storm, which occurred only two days after Lothar, on 28 December, making it difficult to completely ensure that separate datasets were 
used for these two events. December 1999 was particularly unfortunate as storm number 12 was also among the costliest events of the past 2 decades. Storm Vivian (storm 1), very destructive in Switzerland, triggered only local damage in the canton of Vaud, as it struck mainly the alpine region in the south-eastern segment of the canton.

The yearly total insured sums and the number of insured buildings for the canton are also given. Consequently, as mentioned by, for example, Huang et al. (2001) and Pinto et al. (2007), storm losses can be normalised by these yearly total insured sums in order to avoid bias related to inflation and the growth of wealth in the calculations. Economic losses related to each individual storm were therefore divided by the corresponding year's total insured sum over the canton of Vaud to provide normalised storm losses (called loss ratios) that are used in this study. These loss ratios are convenient for insurance companies as they allow long-term loss comparisons, and generally are of a magnitude of $10^{-5}$ (i.e. CHF 0.01 CHF per insured CHF 1000).

Population data is given by the Statistical Office of the canton of Vaud (SCRIS, www.scris.vd.ch). This office provides annual statistics of the number of residents in each of the 368 municipalities of the canton of Vaud for years 1990 to 2010.

\section{Methods}

In order to assess the cubic wind speed term of Eq. (1) for each municipality, daily maximum wind speed records of the 22 weather stations in the area of the canton of Vaud are used (Fig. 1b). These maximum values were normalised by $v_{98}$, raised to the third power, and furthermore regionalised over the canton de Vaud. In this context, two methods are tested and presented in this study, both strongly relying on GIS tools. Furthermore, instead of taking into account the wind speeds, the wind power during a storm event was also computed. These calculations are carried out for an extended area around the borders of the canton of Vaud (Fig. 1b). In order to assess interpolations over a less complex zone, the same loss calculations are also investigated over a more confined and simplified area, focused on the Swiss Plateau but excluding the Alpine and the Jura region (Fig. 1c). Only 9 of the 22 weather stations are located in the Plateau region, but this is acceptable since the terrain is relatively homogeneous and the altitudinal gradient very low. All the interpolations carried out in this study were made using basic kriging methods of the ArcGIS software (ESRI).

\subsection{Interpol}

The first method - INTERPOL - consists in testing the potential for interpolating normalised wind speeds measured at weather stations over the canton of Vaud in order to assess storm damage. The $v_{98}$ values at each weather station are calculated from the listed daily maximum wind speed data of the 1981-2005 period, and the vmax values are provided by the weather stations. The cubic wind speed term in Eq. (1) is then assessed at each station before being interpolated over the canton of Vaud, providing normalised cubic wind speeds at a $1 \mathrm{~km}$ scale, which are finally aggregated to calculate statistics for each municipality. A schematic diagram of this method can be seen in Fig. 2.

\subsection{Map98}

The second method - MAP98 - employs a $v_{98}$ wind map over Switzerland that was created using a combination of GIS tools and generalised additive models (GAMs) to regionalise $v_{98}$ values measured at the Swiss weather stations (Etienne et al., 2010). This map with a spatial resolution of $50 \mathrm{~m}$ resolution was generated using a multi-linear regression model based on relevant topographic layers describing factors likely to disturb wind flows; the resulting $v_{98}$ data provides information on local climate conditions throughout Switzerland and can be used as threshold values in the storm loss model. In this method, vmax values derived from the weather stations are interpolated, before being normalised by the $v_{98}$ data (Fig. 2). The purpose of this method is therefore to apply and test the effectiveness of the $v_{98}$ map created in Etienne et al. (2010) to calculate losses resulting from wind storms.

\subsection{Wind power}

Instead of taking into account the maximum wind speed value only, which has a clear destructive effect on infrastructure and are most commonly used to assess storm damage (Heneka and Ruck, 2004), one can assess the impact of storm duration in the storm damage by considering the cumulative effect of winds above a threshold over time, which can presumably lead to similar consequences. Following this hypothesis, loss calculations are carried out including the complete maximum wind speed time series during the selected storm events, and as in Eq. (1), only the wind speeds that exceed local threshold of $v_{98}$ values is considered. The potentially destructive effects of these extreme winds can be expressed in terms of their associated wind power: the difference of wind power for the measured wind speeds and for the $v_{98}$ is calculated, providing an estimation of the locally exceeded wind power. This method therefore consists of summing up the excesses of wind power during a wind storm event to test the possible sensitivity of economic losses to the storm duration and intensity. An illustration of how this method functions is shown in Fig. 2.

The input data required to evaluate wind power are the maximum wind speed, the temperature and the atmospheric pressure (Manwell et al., 2002). From the continuity equation of fluid mechanics, the mass flow rate $\left(\frac{\mathrm{d} m}{\mathrm{~d} t}\right)$ per unit area is a function of air density $(\rho)$ and maximum wind speed $\left(v_{\max }\right)$ : 

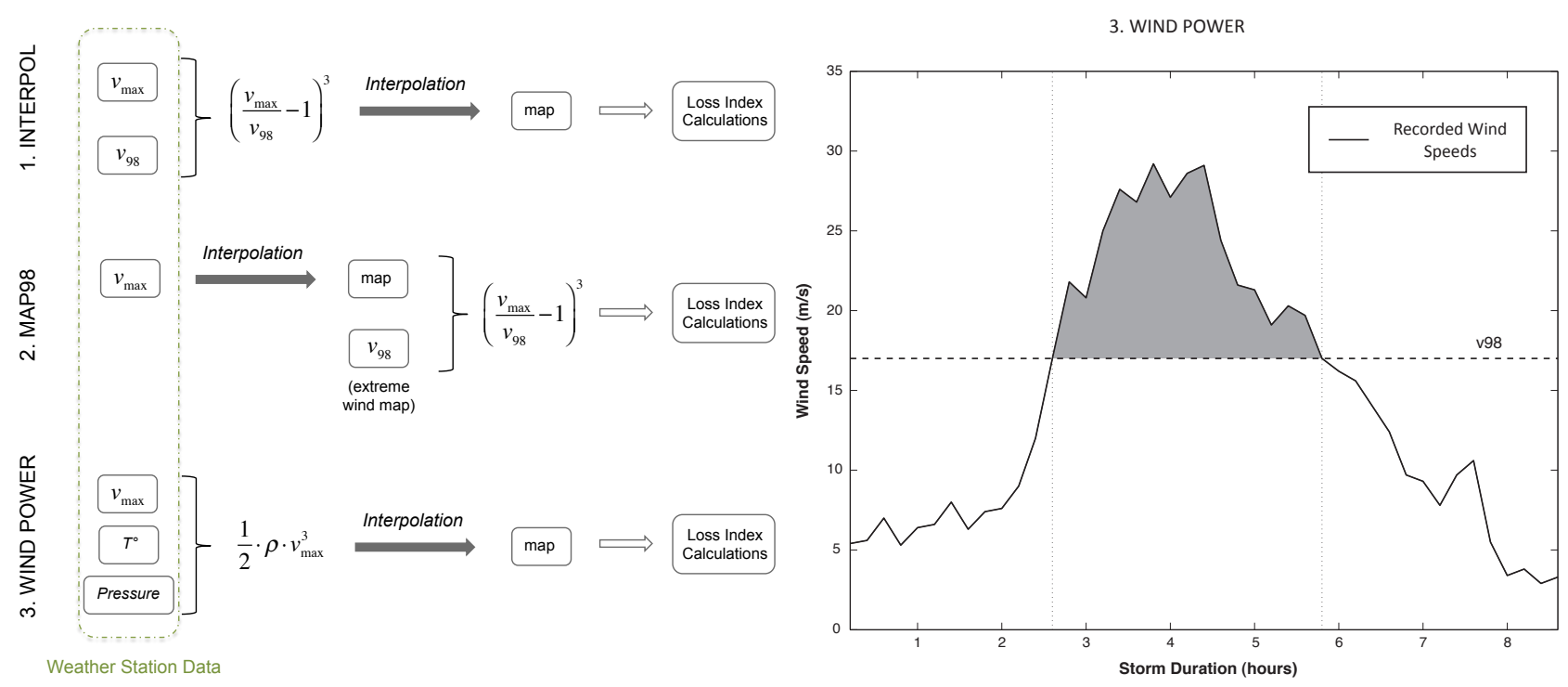

Fig. 2. Left: schematic diagrams describing the main steps of the 3 methods. The top describes the INTERPOL method, the middle the MAP98 and the bottom the WIND POWER. Right: illustration of how the relative wind power is assessed at a given weather station. Wind speeds recorded during a storm are plotted with the local $v_{98}$ value $\left(17 \mathrm{~m} \mathrm{~s}^{-1}\right.$ in the present example). During the storm, whenever the recorded wind speed exceeds the local $v_{98}$ threshold (here roughly between hours 2.5 and 6), the difference between the wind power corresponding to the recorded wind speed and to the $v_{98}$ value is calculated. These differences are integrated over the entire storm event in order to assess the relative wind power at a weather station.

$\frac{\mathrm{d} m}{\mathrm{~d} t}=\rho \cdot v_{\max }$

The air density is calculated from the temperature and the surface pressure using the ideal gas law. Eventually, the kinetic energy (or wind power $P$ ) per unit area is derived:

$P=\frac{1}{2} \cdot \frac{\mathrm{d} m}{\mathrm{~d} t} \cdot v_{\max }^{2}=\frac{1}{2} \cdot \rho \cdot v_{\max }^{3}$.

As in Eq. (1), the wind speed term is therefore also raised to the cube to calculate the loss indices:

Storm Loss $\approx$

$$
A \cdot \underbrace{\sum_{\text {area }} \text { population (area) } \cdot \sum_{\text {area }} \underbrace{\left(\frac{1}{2} \cdot \rho \cdot v_{\max }^{3}\right)}_{\text {for } v_{\max }>v_{98}, \text { else }=0}}_{\text {Loss Index }}+B
$$

Unfortunately, not all of the 22 stations have simultaneous records of pressure, temperature and maximum wind speeds, and therefore roughly half of these weather stations are used for this method. At each station, normalised wind power is calculated before being regionalised.

\section{Results}

Results for all methods for the two studied areas are presented and analysed in this section. Loss indices are calculated for each storm and compared to loss observations by assessing Pearson's determination coefficients. In order to estimate uncertainty, bootstrap techniques described in Efron and Tibshirani (1993) are used: 1000 samples of the 24 storms are generated and corresponding Pearson's coefficients between the calculated loss indices and the loss observations are calculated for each sample. Outputs are shown in Figs. 3 and 4: histograms of the bootstrapped coefficients (left) and scatter graphs (right) of the loss model are provided.

\subsection{Results for the Canton of Vaud}

Figure 3 shows the results of the loss calculations of the three methods for the canton of Vaud. Left are the histograms of the bootstrap operations on the determination coefficients, while the right column shows the scatter-graphs of the model outputs versus the observed normalised damage. The first two methods lead to comparable performance, as the coefficients are both of the order of $R^{2}=0.66-0.68$, and the shapes of the histograms are similar. $R^{2}$ values linked to the second method are, however, less dispersed. The Spearman rank correlation coefficients were also calculated for these 2 methods to compare model outputs to loss observations, leading to values of the order of 0.687 and 0.733 for the first and second method, respectively.

Loss indices based on wind power provided incoherent values for 7 of the 24 storms, as the indices were null or very close to zero. This indicates that the $v_{98}$ thresholds were 

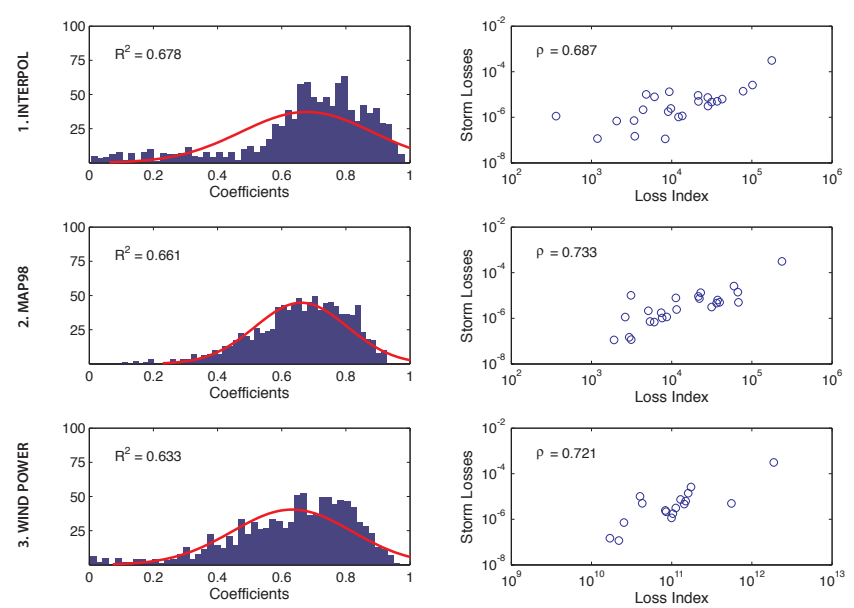

Fig. 3. Model results for the canton of Vaud plotted for the 3 methods: INTERPOL (top), MAP98 (middle) and WIND POWER (bottom). Left: bootstrap results, with histograms of the determination coefficients values for the 1000 samples of the bootstrap. Mean values are shown on the graphs. Right: scatter-graphs, with calculated loss indices on the abscissas and observations on the ordinates (loss ratios, expressed in CHF 0.01 per CHF 1000 insured). All scales are log scales. The Spearman's rank correlation coefficients $(\rho)$ are shown.

only rarely exceeded and that the intensity of these storms was consequently very low. These storms were removed from the input data, and therefore work was carried out with only 17 storms. The damage records of the insurance company once these 7 storms were removed were among the lowest of all 24 storms. Loss estimations with wind power lead to slightly lower results than those of the first 2 methods, with a determination coefficient of $R^{2}=0.63$. The Spearman's rank, however, exceeds 0.7. Moreover, the model was less robust, as the standard deviation of the determination coefficients values is higher.

Despite the large complexity of the study area, simple interpolation techniques are capable of providing good performance in assessing wind storm damage. These 3 methods show that roughly two-thirds of the wind storm damage can be explained by the loss model. For each scatter-graph, the top right point corresponds to the Lothar storm, which clearly exceeds the other storm events in intensity.

Overall results can be observed in Fig. 5. The assessed normalised wind speeds are shown, as well as the corresponding loss index calculations calculated by the MAP98 method. Figure $5 \mathrm{a}$ and $\mathrm{b}$ map the damage estimations for storm 4 (19 January 1995) and the Lothar storm, respectively. The wind speeds are higher for Lothar, clearly leading to greater losses. The regions that exhibit the highest loss estimations for both storms are either located in urban areas (Lausanne, Montreux, Vevey and Yverdon), or where the measured $v_{98}$ values are among the highest. The latter concerns the alpine areas in the south-eastern part of the canton of Vaud, where
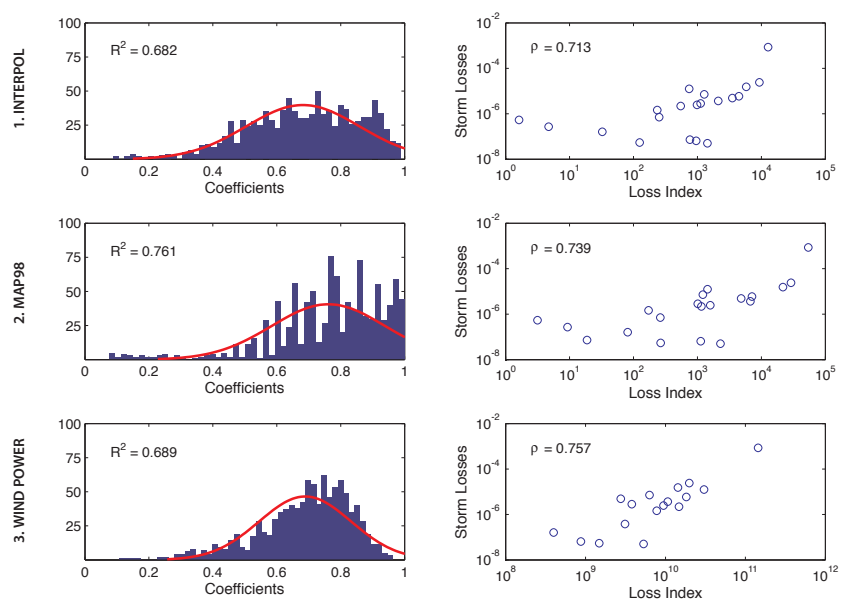

Fig. 4. Model results for the confined zone are plotted for the 3 methods: INTERPOL (top), MAP98 (middle) and WIND POWER (bottom). Left: the bootstrap results, with histograms of the determination coefficients values for the 1000 samples of the bootstrap. Mean values are shown on the graphs. Right: scattergraphs, with calculated loss indices on the abscissas and observations on the ordinates (loss ratios, expressed in CHF 0.01 per CHF 1000 insured). All scales are log scales. The Spearman's rank correlation coefficients $(\rho)$ are shown.

the towns and villages are located at higher elevations. However, the highest losses estimated by the model for these two storms are more closely linked to the most populated areas rather than in zones at higher elevations but with lower populations.

\subsection{Results for the confined area}

The same investigations are carried out for the confined area, with results shown in Fig. 4. All methods provide improved results in terms of both Pearson's determination and Spearman's rank coefficients. The second method (MAP98) provides the best performance, as more than $75 \%$ of the wind storm damage could be explained using the loss model. The histogram shows however a more important dispersion of $R^{2}$ values which can probably be explained by the relatively important dispersion of points on the scatter-graph. Conversely, calculations using the wind power (carried out for the same 17 storms as in Sect. 4.1) show little dispersion and are clustered around a mean value of nearly $R^{2}=0.7$.

These calculations show that when restricted to a less complex area, there is an increase in the effectiveness of the loss model, that now explains close to $70 \%$ of the economic losses. All three methods provide more or less similar results, although the method with the map created by Etienne et al. (2010) leads to better coefficients, but the difference is very low. These enhanced model performance suggest that interpolation of extreme wind speeds were more accurate in this confined area without the mountain ranges. 


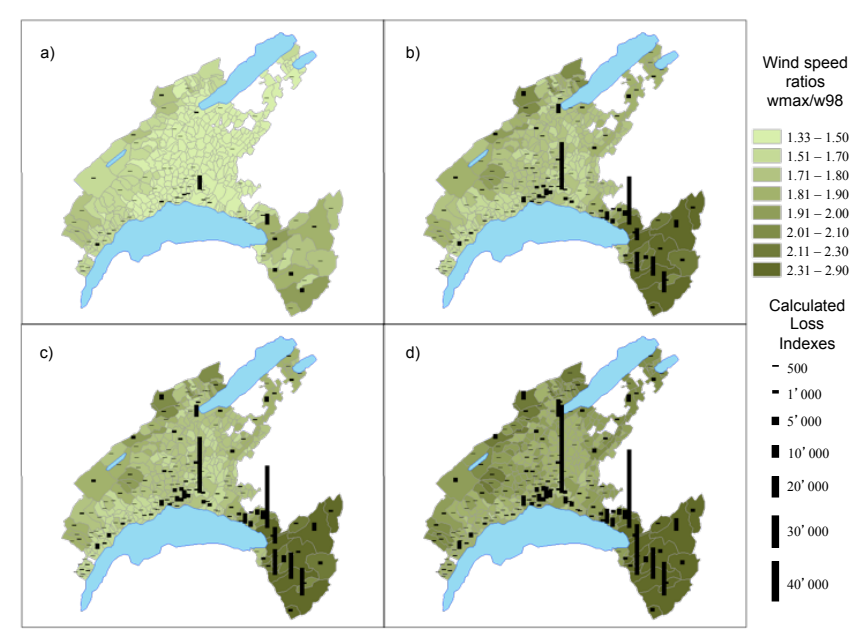

Fig. 5. Loss index calculations, with the corresponding normalised wind speeds for (a) Storm 4, (b) Storm Lothar, (c) Storm Lothar with populations projected for the year 2030 and (d) Storm Lothar with $10 \%$ enhanced wind speeds.

\subsection{Discussion}

The damage model uses population as a proxy for the spatial distribution of insured values. Nevertheless, the latter is provided by the insurance company of the canton of Vaud which communicates yearly insured values for each municipality. Therefore, following the same methodologies as described above, the storm loss model is also applied to the 24 storms using this sparse information, with the loss formula being slightly adapted (i.e. sums over the values rather than sums over the population). Results are comparable to those plotted in Figs. 3 and 4, as determination coefficients were generally raised by $0.1-1$. This indicates that the population data is an accurate approximation to the generally missing insured values when using this storm loss model.

Approximately $70 \%$ of the damage can therefore be explained by the loss model. A list of possible sources of error that could explain the remaining $30 \%$ are suggested and discussed hereafter. These could be linked to the quality of extreme wind speed interpolation, to the insurance loss data and also to the size of the studied area:

- Topography has a marked influence on wind speeds, as important and irregular orographic features are capable of exerting an influence on boundary layer flows (Barry, 1992). The presence of a complex landscape makes any interpolation of wind speeds a very delicate task (Tveito et al., 2008). Consequently, the storm loss model performances for the canton of Vaud could be improved by using finer interpolation methods, as only basic kriging techniques are used in this study.

- Errors could also be linked to the historical damage data: although the observed losses are provided at a very fine resolution, the spatial distribution of economic losses for certain storms shows no particular geographic pattern, as they seem on occasion randomly distributed in the canton of Vaud.

- Perhaps the studied area is too small to genuinely reflect an accurate "storm footprint" as described by Klawa and Ulbrich (2003). Wind storm signatures generally cover areas of over $1000 \mathrm{~km}$ (e.g. Fink et al., 2009), and therefore loss investigations should thus probably be undertaken for a larger area, for example for the whole of Switzerland, in order to have a more realistic view of the storm footprint. Wind heterogeneities in the canton of Vaud for the 24 storms studied are probably linked more to local wind regimes induced by the complex topography than to the spatial distribution of the storm itself. In other words, when working at a very fine resolution such as in this study, small-scale effects can dominate with respect to the behaviour of the storm at a synopticscale.

\subsection{Demographic growth and climate change}

Insured values in the canton of Vaud are expected to increase in the future, due to population growth and an overall increase in the value of property. Storms or other natural hazards are therefore likely to lead to higher economic losses, as shown at a European scale by, for example, Pinto et al. (2007) or Schwierz et al. (2010). Investigations to quantify the economic impacts of these enhanced insured values were carried out and are presented here. Obviously, the future evolution of insured values is not available, but the latter can nevertheless be replaced by the projections of future levels of population. The Statistical Office of the canton of Vaud has provided projections of the evolution of the population for each of the 368 municipalities up to the year 2030. These estimations suggest that compared to year 2000, the overall population of the canton of Vaud is expected to increase by roughly $35 \%$ by 2030 . The evolution is however very heterogeneous, as some municipalities will experience a population decrease, whereas others, mainly located close to the shores of the Lake of Geneva, are likely to undergo considerable demographic growth. Investigations were therefore carried out in order to assess the impact of this population change on economic losses related to wind storms. The loss model was applied to the same 24 studied storms, but using the predicted populations for year 2030. The model takes into account the population data, therefore a shift in these inputs logically leads to an increase in economic losses. Results are listed in column 6 of Table 1, with values indicating the percentage shift in economic losses compared to the original damage. As expected, results closely follow the population increase: the older storms experience the most important damage increase. Moreover, the most severe of the 24 storms suffer the largest shifts, as more municipalities are impacted upon by the storm. Model results for the Lothar storm combined with 
the projected population for 2030 are plotted in Fig. 5c. The latter shows no spectacular contrast with Fig. 5b, but the sensitive differences for each municipality imply an overall major increase in storm damages. At the scale of the canton of Vaud, this study confirms the fact that economic impacts are indeed closely related to population growth.

Future shifts in storm occurrence or storm intensity related to climate change is very uncertain in Switzerland (e.g. Beniston et al., 2007; Rauthe et al., 2010; Goyette, 2010). It is therefore not a trivial matter to predict losses linked to future storminess for the canton of Vaud. Furthermore, assessing return periods of particular storms is delicate and complicated (Della-Marta et al., 2009), especially at the local scales typical of an area such as the one considered in this paper Nevertheless, simple considerations can provide an overview of economic consequences of a small increase in wind speeds compared to current wind storms. For this study, the daily maximum wind speeds recorded at each of the 22 weather stations of the canton of Vaud during the 24 storms have been increased arbitrarily by $3 \%, 5 \%$ and $10 \%$. Input wind speed increase of $3 \%$ and $5 \%$ are in line with the future projections for Western Germany shown in Pinto et al. (2010), whereas investigations with a $10 \%$ shift considers the impact of a "worst case scenario" storm. Estimates have thus been made of losses using these enhanced wind speeds and with the former population statistics. Moreover, the same $v_{98}$ values have been used, although these are likely to change under future climate conditions (Pinto et al., 2010). Results show that with a $3 \%, 5 \%$ and $10 \%$ increase of wind speeds, economic costs for the canton of Vaud would shift by roughly $20 \%, 35 \%$ and $80 \%$, respectively (Table 1 , columns 7-9). As wind speeds are raised to the third power in the loss model, results are clearly highly sensitive to input values. Impacts of $10 \%$ enhanced wind speeds for the Lothar storm can be observed in Fig. 5d. Based on historical gust records of Meteoswiss, the return period of a Lothartype storm is estimated at between 40 and $50 \mathrm{yr}$ (Ceppi et al., 2008); a $10 \%$ increase may seem somewhat exaggerated, but this analysis is aimed at testing model sensitivity to input parameters. Figure $5 \mathrm{~d}$ shows that wind speeds are obviously greater throughout the canton, and the same regions as in previous simulations are exposed to wind damage, but for higher orders of magnitude.

\section{Conclusions}

The purpose of this study has been to evaluate the ability of GIS tools to adequately assess storm damage to infrastructure, and to test the effectiveness of an extreme wind map over Switzerland that was generated in an earlier study. A storm loss model originally investigated in Germany is applied to the canton of Vaud, in Western Switzerland. 24 wind storms that occurred between 1990 and 2010 are analysed. Model outputs are compared to historical storm loss data given by the Property Insurance Company of the canton of Vaud. The study uses only GIS technology to calculate economic losses, whereas similar analyses with fine resolution numerical simulations are being carried out separately (Etienne et al., 2012). Two interpolation methods are used to estimate storm losses, and a third method considering the wind power is also investigated.

Comparisons of the loss model outputs and damage observations show that the model performs well when applied to the canton of Vaud. Bootstrap validation procedures exhibit determination coefficients reaching $R^{2}=0.6$ to 0.68 for all three methods, indicating that all methods provide good estimations for assessing storm damage. These coefficients exceed $R^{2}=0.7$ when the model is applied to a more confined and homogenous area, excluding the complex topographic zones that are the Alps and the Jura. Impacts of population growth and possible enhancements of wind speeds during storms in a changing climate have also been investigated: model outputs react in a roughly linear way to population growth, but are very sensitive to small shifts in wind velocities because of the third-power dependency of damage on wind speed. Both factors highlight potential increases of future economic losses.

These storm loss calculations should be made at larger scales, for example at a national scale, in order to have a more accurate storm footprint. Remarks on the destructive effects of pressure fluctuations on buildings during storms mentioned by Henderson et al. (2009) could be implemented in the loss model. Through this study, the economic impacts of wind storms have been highlighted, and evidence of increasing losses under both future climatic and demographic conditions are emphasised. To prevent extreme losses, it would be necessary to ensure proper building resistance in specific zones where high structural damages have already been observed in the past, or where there is a high density of expensive insured property. This study highlights the need for close collaboration between land and urban planners and climate scientists in order to avert potentially high economic losses during severe storm events.

Acknowledgements. This work has been made possible thanks to the excellent damage data provided by the Property Insurance Company of the canton of Vaud (ECA: Etablissement Cantonal d'Assurances), the population data and the future population estimations provided by the Statistical Office of the Canton of Vaud (Service Cantonal de la Statistique).

Edited by: O. Katz

Reviewed by: U. Ulbrich and one anonymous referee 


\section{References}

Bantle, H.: Program documentation for the Swiss climate data base at the computing center of ETH Zurich, MeteoSwiss publication, Zurich, Switzerland, 8 pp., 1989.

Barredo, J. I.: No upward trend in normalised windstorm losses in Europe: 1970-2008, Nat. Hazards Earth Syst. Sci., 10, 97-104, doi:10.5194/nhess-10-97-2010, 2010.

Barry, R. G.: Mountain Weather and Climate, 3rd Edn., Cambridge University Press, 531 pp., 1992.

Begert, M., Schlegel, T., and Kirchhofer, W.: Homogeneous temperature and precipitation series of Switzerland from 1864 to 2000 , Int. J. Climatol., 25, 65-80, doi:10.1002/joc.1118, 2005.

Beniston, M., Stephenson, D. B., Christensen, O. B., Ferro, C. A. T., Frei, C., Goyette, S., Halsnaes, K., Holt, T., Jylha, K., Koffi, B., Palutikof, J., Scholl, R., Semmler, T., and Woth, K.: Future extreme events in European climate: an exploration of regional climate model projections, Climatic Change, 81, 71-95, doi:10.1007/s10584-006-9226-z, 2007.

Bohle-Carbonell, M.: Wind and currents - response patterns of lake geneva, Ann. Geophys., 9, 82-90, 1991, http://www.ann-geophys.net/9/82/1991/.

Bresch, D. N., Bisping, M., and Lemecke, G.: Storm over Europe: An Underestimated Risk, Swiss Reinsurance Company, 27 pp., 2000.

Ceppi, P., Della-Marta, P. M., and Appenzeller, C.: Extreme Value Analysis of Wind Speed Observations over Switzerland, Meteoswiss Publication, 219, 43 pp., 2008.

Della-Marta, P. M., Mathis, H., Frei, C., Liniger, M. A., Kleinn, J., and Appenzeller, C.: The return period of wind storms over Europe, Int. J. Climatol., 29, 437-459, doi:10.1002/joc.1794, 2009.

Della-Marta, P. M., Liniger, M. A., Appenzeller, C., Bresch, D. N., Kollner-Heck, P., and Muccione, V.: Improved Estimates of the European Winter Windstorm Climate and the Risk of Reinsurance Loss Using Climate Model Data, J. Appl. Meteorol. Climatol., 49, 2092-2120, doi:10.1175/2010JAMC2133.1, 2010.

Donat, M. G., Pardowitz, T., Leckebusch, G. C., Ulbrich, U., and Burghoff, O.: High-resolution refinement of a storm loss model and estimation of return periods of loss-intensive storms over Germany, Nat. Hazards Earth Syst. Sci., 11, 2821-2833, doi:10.5194/nhess-11-2821-2011, 2011.

Dorland, C., Tol, R. S. J., and Palutikof, J. P.: Vulnerability of the Netherlands and Northwest Europe to Storm Damage under Climate Change, Climatic Change, 43, 513-535, 1999.

Efron, B. and Tibshirani, R.: An introduction to the bootstrap, Chapman and Hall, New York, 1993.

Etienne, C., Lehmann, A., Goyette, S., Lopez-Moreno, J. I., and Beniston, M.: Spatial Predictions of Extreme Wind Speeds over Switzerland Using Generalized Additive Models, J. Appl. Meteorol. Climatol., 49, 1956-1970, doi:10.1175/2010jamc2206.1, 2010.

Etienne, C., Goyette, S., and Kuszli, C. A.: Numerical investigations of extreme winds over Switzerland during 1990-2010 winter storms with the Canadian Regional Climate Model, Theor. Appl. Climatol., doi:10.1007/s00704-012-0800-1, online first, 2012.

Fink, A. H., Brücher, T., Ermert, V., Krüger, A., and Pinto, J. G.: The European storm Kyrill in January 2007: synoptic evolution, meteorological impacts and some considerations with respect to climate change, Nat. Hazards Earth Syst. Sci., 9, 405-423, doi:10.5194/nhess-9-405-2009, 2009.
Goyette, S.: Synoptic conditions of extreme windstorms over Switzerland in a changing climate, Clim Dynam., 36, 845-866, doi:10.1007/s00382-010-0820-4, 2010.

Henderson, D. J., Ginger, J. D., Morrison, M. J., and Kopp, G. A.: Simulated tropical cyclonic winds for low cycle fatigue loading of steel roofing, Wind Struct., 12, 383-400, 2009.

Heneka, P. and Ruck, B.: Development of a storm damage risk map of Germany - A review of storm damage functions, International Conference for Disasters and Society, Karlsruhe, 2004.

Heneka, P., Hofherr, T., Ruck, B., and Kottmeier, C.: Winter storm risk of residential structures - model development and application to the German state of Baden-Württemberg, Nat. Hazards Earth Syst. Sci., 6, 721-733, doi:10.5194/nhess-6-721-2006, 2006.

Hoinka, K. P.: Observation of the air-flow over the Alps during a Foehn event, Q. J. R. Meteorol. Soc., 111, 199-224, doi:10.1256/smsqj.46708, 1985.

Huang, Z., Rosowsky, D. V., and Sparks, P. R.: Long-term hurricane risk assessment and expected damage to residential structures, Reliability Eng. System Saf., 74, 239-249, 2001.

Klawa, M. and Ulbrich, U.: A model for the estimation of storm losses and the identification of severe winter storms in Germany, Nat. Hazards Earth Syst. Sci., 3, 725-732, doi:10.5194/nhess-3725-2003, 2003.

Lambert, S. J. and Fyfe, J. C.: Changes in winter cyclone frequencies and strengths simulated in enhanced greenhouse warming experiments: results from the models participating in the IPCC diagnostic exercise, Clim. Dynam., 26, 713-728, doi:10.1007/s00382-006-0110-3, 2006.

Leckebusch, G. C., Ulbrich, U., Frohlich, L., and Pinto, J. G.: Property loss potentials for European midlatitude storms in a changing climate, Geophys. Res. Lett., 34, L05703, doi:10.1029/2006g1027663, 2007.

Manwell, J. F., McGowan, J. G., and Rogers, A. L.: Wind Energy Explained - Theory, Design and Application, Wiley ed., Chichester, 2002.

MunichRe: Winter storms in Europe (II) - Analysis of 1999 losses and loss potentials, Munich Reinsurance Company, 2001.

Pinto, J. G., Fröhlich, E. L., Leckebusch, G. C., and Ulbrich, U.: Changing European storm loss potentials under modified climate conditions according to ensemble simulations of the ECHAM5/MPI-OM1 GCM, Nat. Hazards Earth Syst. Sci., 7, 165-175, doi:10.5194/nhess-7-165-2007, 2007.

Pinto, J. G., Neuhaus, C. P., Leckebusch, G. C., Reyers, M., and Kerschgens, M.: Estimation of wind storm impacts over Western Germany under future climate conditions using a statistical-dynamical downscaling approach, Tellus, 62A, 188201, doi:10.1111/j.1600-0870.2009.00424.x, 2010.

Rauthe, M., Kunz, M., and Kottmeier, C.: Changes in wind gust extremes over Central Europe derived from a small ensemble of high resolution regional climate models, Meteorol. Z., 19, 299312, doi:10.1127/0941-2948/2010/0350, 2010.

Schwierz, C., Kollner-Heck, P., Mutter, E. Z., Bresch, D. N., Vidale, P. L., Wild, M., and Schar, C.: Modelling European winter wind storm losses in current and future climate, Climatic Change, 101, 485-514, doi:10.1007/s10584-009-9712-1, 2010.

Schüepp, M., Schiesser, H. H., Huntrieser, H., Scherrer, H. U., and Schmidtke, H.: The Windstorm "Vivian" of 27 February 1990: About the Meteorological Development, Wind Forces and Dam- 
age Situation in the Forest of Switzerland, Theor. Appl. Climatol., 49, 183-200, 1994.

SwissRe: Storms over Europe - An underestimated risk, Swiss Reinsurance Company, Swiss Re publishing., 29 pp., 2000.

Tveito, O. E., Wegehenke, M., van der Wel, F., and Dobesch, H.: The Use of Geographic Information Systems in Climatology and Meteorology, Office for Official Publications of the European Communities, 245 pp., 2008.

Ulbrich, U., Leckebusch, G. C., and Pinto, J. G.: Extra-tropical cyclones in the present and future climate: a review, Theor. Appl. Climatol., 96, 117-131, doi:10.1007/s00704-008-0083-8, 2009.
Unanwa, C. O., McDonald, J. R., Mehta, K. C., and Smith, D. A.: The development of wind damage bands for buildings, J. Wind Eng. Ind. Aerodyn., 84, 119-149, 2000.

Wanner, H. and Furger M.: The Bise - climatology of a regional wind north of the Alps., Meteor. Atmos. Phys., 43, 105-115, doi:10.1007/bf01028113, 1990.

Wernli, H., Dirren, S., Liniger, M. A., and Zillig, M.: Dynamical aspects of the life cycle of the winter storm "Lothar" (24-26 December 1999), Q. J. R. Meteorol. Soc., 128, 405-429, 2002. 